\title{
PULMONARY HEMODYNAMICS CONTRIBUTE TO INDICATE PRIORITY FOR LUNG TRANSPLANTATION IN PATIENTS WITH CYSTIC FIBROSIS
}

Federico Venuta, MD

Erino A. Rendina, $\mathrm{MD}^{\mathrm{a}}$

Giorgio Della Rocca, $\mathrm{MD}^{\mathrm{b}}$

Tiziano De Giacomo, MD $^{\mathrm{a}}$

Francesco Pugliese, MD ${ }^{\mathrm{b}}$

Anna Maria Ciccone, $\mathrm{MD}^{\mathrm{a}}$

Carmine D. Vizza, MD

Giorgio Furio Coloni, MD

Sponsor: G. Alexander Patterson, MD
Objective: Lung transplantation is a viable option for patients with cystic fibrosis. The current strategy of selection, based on spirometry and deterioration of quality of life, results in a high mortality on the waiting list. We reviewed the case histories of patients with cystic fibrosis accepted for lung transplantation to ascertain whether pulmonary hemodynamics could contribute to predict life expectancy.

Methods: Forty-five patients with cystic fibrosis were accepted: 11 died on the waiting list (group I), 24 underwent transplantation (group II), and 10 are still waiting (group III). During evaluation we recorded spirometry, oxygen requirement, ratio of arterial oxygen tension to inspired oxygen fraction $\left(\mathrm{PaO}_{2} / \mathrm{FIO}_{2}\right)$, arterial carbon dioxide tension $\left(\mathrm{PaCO}_{2}\right)$, 6-minute walk test results, right ventricular ejection fraction, echocardiography, and pulmonary hemodynamics. We compared data from group I, II, and III patients. A comparison was also made within group II between the data collected at the time of evaluation and at the time of transplantation to quantify the deterioration during the waiting time.

Results: The waiting time, spirometry, 6-minute walk test results, and right ventricular ejection fraction did not differ among the three groups. A statistically significant difference was found for $\mathrm{PaO}_{2} / \mathrm{FIO}_{2}, \mathrm{PaCO}_{2}$, mean pulmonary artery pressure, cardiac index, pulmonary arterial wedge pressure, and intrapulmonary shunt between groups I and II. Groups I and III showed statistically significant differences for mean pulmonary artery pressure, $\mathrm{PaO}_{2} / \mathrm{FIO}_{2}$, and systemic vascular resistance indexed. No differences were observed between groups II and III. The comparison within group II showed a significant deterioration of pulmonary hemodynamics during the waiting time.

Conclusions: Pulmonary hemodynamics are worst in patients dying on the waiting list and deteriorate significantly during the waiting time. They may thus contribute to establish priority for lung transplantation in patients with cystic fibrosis. (J Thorac Cardiovasc Surg 2000;119:682-9) ung transplantation is considered a viable therapeutic option for patients with cystic fibrosis $(\mathrm{CF}) .^{1,2}$ Timing of referral is crucial to improve results and minimize mortality on the waiting list. Potential candidates should be selected according to rigid criteria and only those most likely to benefit from surgery should be accepted; however, prognosis in CF has often been dif-

From the University of Rome "La Sapienza," Departments of Thoracic Surgery, ${ }^{\mathrm{a}}$ Anesthesiology, ${ }^{\mathrm{b}}$ and Cardiology, ${ }^{\mathrm{c}}$ Rome, Italy.

Read at the Seventy-ninth Annual Meeting of The American Association for Thoracic Surgery, New Orleans, La, April 18-21, 1999.

Received for publication April 22, 1999; revisions requested July 7, 1999; revisions received Nov 22, 1999; accepted for publication Nov 24, 1999. ficult to predict because of the variable course of the disease in the individual patient. Data obtained in other groups of lung transplantation candidates are not applicable to CF because of the many peculiarities of this disease. Consequently, the current strategy, based on the decline of pulmonary function test results and oxygenation, deterioration of quality of life, and

\footnotetext{
Address for reprints: Federico Venuta, MD, Cattedra di Chirurgia Toracica, Policlinico Umberto I, University of Rome "La Sapienza," Via le del Policlinico, 00100 Rome, Italy (E-mail: Fevenuta@tin.it).

Copyright (C 2000 by The American Association for Thoracic Surgery. $0022-5223 / 2000 \$ 12.00+0 \quad \mathbf{1 2} / \mathbf{6} / \mathbf{1 0 4 7 0 2}$ doi:10.1067/mtc.2000.104702
} 
increased frequency of hospitalization, is often imprecise; as a result, mortality on the waiting list is sill high (around 20\%). ${ }^{3-6}$ Pulmonary transplantation requires rationing of the donor resources because of the large discrepancy between donor and recipient numbers, and little aid can be expected by temporary mechanical supports. In the United States, lung allocation is administered by the United Network for Organ Sharing (UNOS) and determined by the recipient waiting time within the region where the donor is located. This policy favors patients who can survive longer on the waiting list. ${ }^{7,8}$ In Italy, like other European countries, ${ }^{9}$ a good deal of local autonomy is allowed in favor of patients with the worst clinical setting and the most advanced pulmonary dysfunction; however, this may not be the best way to determine where in the waiting list each patient might be placed.

For all the aforementioned reasons, additional parameters should be evaluated to indicate at which point of the "transplant window" 10 each patient should be located once on the waiting list and thus contribute to give him or her priority for lung transplantation.

We reviewed our experience with lung transplantation for the treatment of CF to evaluate the possibility that assessment of pulmonary hemodynamics could improve referral patterns and the determination of priority among potential recipients.

\section{Patients and methods}

Between October 1996 and January 1999, 45 consecutive patients with $\mathrm{CF}$ were accepted in our lung transplantation program; this is the total group of CF patients entered on our waiting list during the study period. There were 30 female and 15 male patients (aged 7-38 years, mean $22 \pm 5$ years). Preoperative evaluation and selection were performed according to standard criteria. The general criteria for inclusion in the waiting list for lung transplant candidates were as follows:

- Life expectancy less than 18 to 24 months

- No significant renal or hepatic disease

- No evidence of malignancy for more than 5 years

- Ambulatory

- Able to participate in the rehabilitation program

- Psychosocial stability

- Previous pleural procedures acceptable

The guidelines for timing referral for patients with $\mathrm{CF}$ were as follows:

- Postbronchodilator forced expiratory volume in 1 second $\left(\mathrm{FEV}_{1}\right)$ less than $30 \%$ of predicted

- Resting hypoxia $\left(\mathrm{PaO}_{2}\right.$ less than $\left.55 \mathrm{~mm} \mathrm{Hg}\right)$

- Hypercapnia

- Increased frequency and severity of exacerbations

- Increased frequency and duration of hospitalizations

- Progressive and uncontrolled weight loss
Twenty-four (53\%) patients underwent transplantation, 11 (24\%) died on the waiting list, and $10(23 \%)$ are still waiting. At the time of evaluation, pulmonary function tests (PFT4 COSMED; Padova, Italy) were done according to the American Thoracic Society standards; we also recorded body weight (percent of predicted), Schwachman score, supplemental oxygen requirement, ratio of arterial oxygen tension to inspired oxygen fraction $\left(\mathrm{PaO}_{2} / \mathrm{FIO}_{2}\right)$, arterial carbon dioxide tension $\left(\mathrm{PaCO}_{2}\right), 6$-minute walk test results, and right ventricular ejection fraction. Transthoracic 2-dimensional and M-mode echocardiography (Hewlett-Packard 2500, Andover, Mass) have been performed for the examination of right ventricular morphology with a phased-array imaging system with a $2.5 \mathrm{MHz}$ transducer. Right ventricular morphology was classified in 4 groups: (A) normal; (B) hypertrophy without dilatation; (C) dilatation without hypertrophy; and (D) hypertrophy and dilatation. The right ventricular area was calculated by planimetry from the apical 4-chamber view at end-diastole, ${ }^{11}$ and it was considered to be enlarged if the right ventricular area was more than $20.4 \mathrm{~cm}^{2}$. Right ventricular wall hypertrophy was considered to be present when the right ventricular wall thickness was more than $0.5 \mathrm{~cm} .{ }^{11}$ All patients underwent direct right heart catheterization for assessment of pulmonary hemodynamics. A balloon catheter was inserted through the femoral vein and advanced to the capillary wedge position; no complication related to this procedure was observed. The following measurements were recorded: heart rate, mean arterial pressure, mean pulmonary artery pressure (mPA), central venous pressure, pulmonary arterial wedge pressure (PAWP), and cardiac output. Cardiac index was calculated as well as indexed pulmonary and systemic vascular resistance (PVRI and SVRI) and intrapulmonary shunt $(\mathrm{Q} / \mathrm{Qt})$. All measurements were performed with the patient breathing $100 \%$ oxygen. Pulmonary hypertension was graded as mild/moderate (mPA between 20 and $25 \mathrm{~mm} \mathrm{Hg}$ ) and severe (mPA > $25 \mathrm{~mm} \mathrm{Hg}$ ). In patients with pulmonary hypertension, hemodynamic measurements were repeated after administration of inhaled nitric oxide (40 ppm) (Politron $\mathrm{NO}$ and $\mathrm{NO}_{2}$; Dräger, Lubeck, Germany). The radionuclide studies were performed by gated equilibrium radionuclide ventriculography after a peripheral intravenous injection of $750 \mathrm{MBq}$ technetium $99 \mathrm{~m}$ human serum albu$\min$. A right ventricular ejection fraction of $45 \%$ was considered the lower normal limit. We compared data collected at the time of evaluation from patients dying on the waiting list (group I) with data on patients undergoing lung transplantation (group II) and patients still on the waiting list (group III). A comparison was also made within group II between the data collected at the time of evaluation and at the time of transplantation to quantify the functional deterioration during the waiting time. Hemodynamic measures were repeated after induction of anesthesia, intubation, and double lung mechanical ventilation to evaluate these parameters in the absence of any emotional impact.

Statistical analyses among groups I, II, and III were performed with the analysis of variance procedure (ANOVA); 
Table I. Demographic and functional variables at the time of evaluation for patients dying while on the waiting list (group I), reaching the time of transplantation (group II), and still on the waiting list (group III)

\begin{tabular}{lcccc}
\hline & Group I & Group II & Group III & P value \\
\hline Age (y) & $23 \pm 7$ & $20 \pm 4$ & $21 \pm 3$ & .3 \\
Weight (\% of predicted) & $82 \pm 7$ & $84 \pm 7$ & $84 \pm 6$ & .2 \\
FVC (\%) & $36 \pm 7$ & $37 \pm 8$ & $38 \pm 6$ & .4 \\
FEV & $18 \pm 4$ & $21 \pm 6$ & $21 \pm 4$ & .4 \\
RVEF (\%) & $46 \pm 8$ & $50 \pm 5$ & $51 \pm 5$ & .2 \\
6MWT (m) & $295 \pm 106$ & $319 \pm 82$ & $338 \pm 86$ & .5 \\
Shwachman score & $47 \pm 2$ & $46 \pm 4$ & $49 \pm 6$ & .2 \\
Waiting time (d) & $112(28-238)$ & $121(1-281)$ & $178(45-328)$ & .09
\end{tabular}

$F V C$, Forced vital capacity; $F E V_{l}$, forced expiratory volume in 1 second; $R V E F$, right ventricular ejection fraction; $6 M W T$, 6-minute walk test.

Table II. Echocardiographic study to assess morphology of the right ventricle at the time of evaluation for group I, II and III patients $(\mathrm{P}=.5)$

\begin{tabular}{lcccc}
\hline & & & & Hypertrophy + \\
Nilatation
\end{tabular}

multiple comparisons among the three groups were performed with the Tukey Studentized range test to evaluate the specific significance of each group. The influence of each variable on the outcome was evaluated with the Cox proportional hazards model censoring patients at either the latest day of follow-up alive on the waiting list or at the time of transplantation. A $\chi^{2}$ test was used to analyze the echocardiographic parameters. Repeated-measures analysis of variance was used to study the response to inhaled nitric oxide in group I, II and III patients with pulmonary hypertension. Computations were performed with an SAS personal computer (version 6.12; SAS Institute Inc, Cary, NC).

\section{Results}

Twenty-two of the 24 patients who underwent transplantation are alive (mean follow-up, 16.8 months; 2year survival, $88 \%$ ); infection was the cause of death in the 2 patients not surviving the immediate postoperative course. Three patients required cardiopulmonary bypass during transplantation. The mean time on the waiting list for groups I, II, and III was, respectively, 112 days (28-238 days), 121 days (1-281 days), and 178 days $(45-328$ days) $(P=.09)$. All patients needed continuous supplemental oxygen. Pseudomonas cepacia colonization was equally present in the three groups: 2 patients in group I (18\%), 3 patients in group II (13\%), and 2 patients in group III (20\%). No patient in either group had clinically important liver dysfunc- tion. The ANOVA procedure showed no differences for age, weight, Schwachman score, spirometric data, 6minute walk test, and right ventricular ejection fraction between groups I, II, and III (Table I) nor between echocardiographic parameters $(P=.5)$ (Table II). A statistically significant difference was found for $\mathrm{PaO}_{2} / \mathrm{FIO}_{2}, \mathrm{PaCO}_{2}, \mathrm{mPA}$, cardiac output, cardiac index, PAWP, Qs/Qt, SVRI (Table III), and supplemental oxygen requirement $(P=.02)$; the Tukey test showed a significant comparison at the .05 level between groups I and II for all these parameters; differences between groups I and III were present only for $\mathrm{mPA}, \mathrm{PaCO}_{2}$, and SVRI. No statistically significant difference was observed between groups II and III. Mild to moderate pulmonary hypertension was present in 1 patient $(9 \%)$ in group I, 10 (42\%) in group II, and $2(20 \%)$ in group III; severe pulmonary hypertension was present in 10 $(91 \%)$ patients in group I, $2(8 \%)$ in group II, and 3 $(30 \%)$ in group III $(P=.02)$. All patients with pulmonary hypertension were tested with inhaled nitric oxide, and the percentage of responders and grade of response did not differ among the three groups; the degree of response to inhaled nitric oxide depended only on the preadministration mPA: in fact, independently from grouping, the condition of patients with severe pulmonary hypertension (mean $35 \pm 10 \mathrm{~mm} \mathrm{Hg}$ ) improved considerably with inhaled nitric oxide (mean $28 \pm 9 \mathrm{~mm} \mathrm{Hg})(P=.0006)$. The comparison within 
Table III. Blood gas analysis and hemodynamic variables in group I, II and III patients at the time of evaluation

\begin{tabular}{lcccc}
\hline & Group I & Group II & Group III & P value \\
\hline $\mathrm{HR}($ beats/min) & $120 \pm 21$ & $105 \pm 20$ & $104 \pm 13$ & .1 \\
$\mathrm{CO}(\mathrm{L} / \mathrm{min})$ & $6.2 \pm 1.3$ & $4.9 \pm 1$ & $5.8 \pm 1.5$ & .02 \\
$\mathrm{mAP}(\mathrm{mm} \mathrm{Hg})$ & $77 \pm 7$ & $79 \pm 8$ & $80 \pm 15$ & .85 \\
$\mathrm{mPA}(\mathrm{mm} \mathrm{Hg})$ & $35 \pm 12$ & $22 \pm 6$ & $23 \pm 6$ & .001 \\
$\mathrm{CVP}(\mathrm{mm} \mathrm{Hg})$ & $2.6 \pm 2$ & $2 \pm 1.5$ & $3 \pm 1.6$ & .6 \\
$\mathrm{PAWP}(\mathrm{mm} \mathrm{Hg})$ & $6.6 \pm 2.4$ & $3.2 \pm 2$ & $5.1 \pm 3.5$ & .007 \\
$\mathrm{CI}\left(\mathrm{L} \cdot \mathrm{min}^{-1} \cdot \mathrm{m}^{-2}\right)$ & $4.6 \pm 1$ & $3.5 \pm 0.6$ & $3.8 \pm 0.7$ & .005 \\
$\mathrm{SVRI}\left(\mathrm{dynes} \cdot \mathrm{s}^{-5} \cdot \mathrm{m}^{-2}\right)$ & $1334 \pm 240$ & $1794 \pm 371$ & $1703 \pm 436$ & .01 \\
$\mathrm{PVRI}\left(\mathrm{dynes} \cdot \mathrm{s}^{-5} \cdot \mathrm{m}^{-2}\right)$ & $492 \pm 100$ & $450 \pm 139$ & $392 \pm 153$ & .2 \\
$\mathrm{PaO}_{2} / \mathrm{FIO}$ & $191 \pm 54$ & $274 \pm 63$ & $258 \pm 27$ & .002 \\
$\mathrm{PaCO}_{2}(\mathrm{~mm} \mathrm{Hg})$ & $65 \pm 23$ & $45 \pm 5$ & $50 \pm 3$ & .002 \\
$\mathrm{Qs} / \mathrm{Qt}(\%)$ & $31 \pm 7$ & $23 \pm 3$ & $27 \pm 4$ & .004 \\
\hline
\end{tabular}

$H R$, Heart rate; $C O$, cardiac output; $m A P$, mean arterial pressure; $m P A$, mean pulmonary artery pressure; $C I$, cardiac index; $S V R I$, systemic vascular resistance indexed; $Q s / Q t$, intrapulmonary shunt.

Table IV. Functional and hemodynamic variables in patients (group II) reaching the time of transplantation; data were collected at the time of evaluation (left) and at the time of transplantation (right)

\begin{tabular}{lccl}
\hline & Evaluation & Transplantation & $\mathrm{P}$ value \\
\hline $\mathrm{FEV}_{1}(\mathrm{~L} / \mathrm{s})$ & $21 \pm 6$ & $20 \pm 4.5$ & .4 \\
Suppl. $\mathrm{O}_{2}(\mathrm{~L} / \mathrm{min})$ & $1.7 \pm 1$ & $2.4 \pm 1$ & .06 \\
$\mathrm{HR}(\mathrm{beats} / \mathrm{min})$ & $105 \pm 20$ & $123 \pm 17$ & .01 \\
$\mathrm{CO}(\mathrm{L} / \mathrm{min})$ & $4.9 \pm 1$ & $5.4 \pm 1.6$ & .3 \\
$\mathrm{mAP}(\mathrm{mm} \mathrm{Hg})$ & $79 \pm 8$ & $86 \pm 10$ & .01 \\
$\mathrm{mPA}(\mathrm{mm} \mathrm{Hg})$ & $22 \pm 6$ & $32 \pm 10$ & .005 \\
$\mathrm{CVP}(\mathrm{mm} \mathrm{Hg})$ & $2 \pm 1.5$ & $4.8 \pm 3.8$ & .1 \\
$\mathrm{PAWP}(\mathrm{mm} \mathrm{Hg})$ & $3.2 \pm 2$ & $13 \pm 6$ & .0001 \\
$\mathrm{CI}\left(\mathrm{L} \cdot \mathrm{min}^{-1} \cdot \mathrm{m}^{-2}\right)$ & $3.5 \pm 0.6$ & $3.8 \pm 0.9$ & .2 \\
$\mathrm{SVRI}\left(\mathrm{dynes} \cdot \mathrm{s}^{-5} \cdot \mathrm{m}^{-2}\right)$ & $1794 \pm 371$ & $1846 \pm 538$ & .3 \\
$\mathrm{PVRI}\left(\mathrm{dynes} \cdot \mathrm{s}^{-5} \cdot \mathrm{m}^{-2}\right)$ & $450 \pm 139$ & $421 \pm 161$ & .7 \\
$\mathrm{PaO} / \mathrm{FIO}$ & $274 \pm 63$ & $210 \pm 28$ & .5 \\
$\mathrm{PaCO}_{2}(\mathrm{~mm} \mathrm{Hg})$ & $45 \pm 5$ & $52 \pm 9$ & .8 \\
$\mathrm{Qs}_{\mathrm{Q}}(\%)$ & $23 \pm 3$ & $38 \pm 4$ & .004 \\
\hline
\end{tabular}

$F E V_{l}$, Forced expiratory volume in 1 second; Suppl. $O_{2}$, supplemental oxygen requirement; $H R$, heart rate; $C O$, cardiac output; $m A P$, mean arterial pressure; $m P A$, mean pulmonary artery pressure; $C V P$, central venous pressure; $P A W P$, pulmonary arterial wedge pressure; SVRI, systemic vascular resistance indexed; PVRI, pulmonary vascular resistance indexed; $Q s / Q t$, intrapulmonary shunt.

group II at the time of evaluation and the time of transplantation showed a significant deterioration of pulmonary hemodynamics during the waiting time, as well as a deterioration in $\mathrm{PaO}_{2} / \mathrm{FIO}_{2}$ and $\mathrm{PaCO}_{2}$ (Table IV). After induction of anesthesia, mPA did not show any modification ( $32 \pm 10 \mathrm{~mm} \mathrm{Hg}$ vs $30 \pm 6 \mathrm{~mm} \mathrm{Hg}$ ); other hemodynamic parameters and oxygenation were relatively modified by anesthesia and mechanical ventilation. The Cox proportional hazards model demonstrated a trend toward an increased risk of death on the waiting list for patients showing a deranged heart rate,
Table V. Results of Cox proportional hazards model

\begin{tabular}{lcc}
\hline Variable & Cox coefficient \pm SE & P value \\
\hline $\mathrm{HR}$ & $0.03 \pm 0.01$ & .08 \\
$\mathrm{mPA}$ & $0.03 \pm 0.01$ & .08 \\
$\mathrm{CI}$ & $0.4 \pm 0.2$ & .09 \\
$\mathrm{SVRI}$ & $0.001 \pm 0.0009$ & .05 \\
$\mathrm{PaO} / \mathrm{FIO}_{2}$ & $0.01 \pm 0.004$ & .01 \\
$\mathrm{Qs} / \mathrm{Qt}$ & $0.08 \pm 0.04$ & .04 \\
Suppl. $\mathrm{O}_{2}$ & $1.14 \pm 0.3$ & .001 \\
\hline
\end{tabular}

$H R$, Heart rate; $m P A$, mean pulmonary artery pressure; $C I$, cardiac index; $S V R I$, systemic vascular resistance indexed; $Q s / Q t$, intrapulmonary shunt; Suppl. $\mathrm{O}_{2}$, supplemental oxygen requirement.

mPA, cardiac index, SVRI, $\mathrm{PaO}_{2} / \mathrm{FIO}_{2}$, Qs/Qt, and an increased supplemental oxygen requirement (Table V).

\section{Discussion}

Potential recipients of lung transplants generally exceed the supply of donors; for this reason a number of patients will die on the waiting list. Previous reports showed that patients with pulmonary fibrosis and $\mathrm{CF}$ are at higher risk of death during the waiting time than are other lung transplant candidates. ${ }^{7,8,10,12}$ Twentyfour percent of our patients with CF did not live long enough to undergo transplantation, a figure that is in line with other reports. ${ }^{2-6}$ Death continues to be due in most cases to progression of respiratory failure and infectious exacerbations; cor pulmonale and pulmonary hypertension are associated in the late phases of the disease. ${ }^{11,13-15}$ Timing of referral is a crucial ethical issue to reduce mortality on the waiting list and improve results; however, actual predictors of death for patients with $\mathrm{CF}$ are difficult to quantitate. ${ }^{3-5,16-21}$ They should predict an 18-month survival and indicate the possible beginning of the "transplant window." 
Pulmonary function tests are useful indicators: an $\mathrm{FEV}_{1}$ less than $30 \%$ of predicted helps to identify a risk of death of $50 \%$ within 2 years ${ }^{3.5}$ and it might be useful to indicate when the "transplant window" should be opened. Further deterioration of $\mathrm{FEV}_{1}$ is extremely slow after reaching values lower than $20 \%$ of predicted, as confirmed by our data (Table IV); on the other hand, a sudden decrease may be associated with life-threatening exacerbations and therefore may not follow the predicted pattern. Hypercapnia presents a bizarre course: all patients show moderate hypercapnia at the time of evaluation, and this is considered an inclusion criterion. $\mathrm{PaCO}_{2}$ may remain stable for a long time and increase further only during infectious exacerbations or increase slightly and then raise suddenly in the final phase of the clinical course; it may also remain high after infectious exacerbations or return to the previous level. Noninvasive ventilation may contribute to amelioration of tolerance of hypercapnia and prolong the waiting time. For this reason, hypercapnia might account for an advanced stage of the disease, but it is unpredicatable at which phase of the "transplant window" each hypercapnic patient should be placed. Also, hypoxia should be interpreted the same way. The 6minute walk test has been reported as a useful predictive factor ${ }^{21}$ : $400 \mathrm{~m}$ appears to be a reasonable cutoff for listing patients for lung transplantation. However, patients with $\mathrm{CF}$ show a high exercise tolerance if compared with all the other groups, possibly because of a blunted sensation of dyspnea related to their lifelong battle with the disease. The 6-minute walk test results may deteriorate dramatically after infectious exacerbations. Most patients listed in our program showed a 6minute walk distance lower than $400 \mathrm{~m}$, probably related to a more advanced stage of the disease at the time of referral, at least at the beginning of our experience. However, there was no difference between patients dying on the waiting list and those having a successful transplantation; for this reason, we consider the 6minute walk test, along with other inclusion parameters, as a good test to accept patients in the transplant program, but it may be unreliable to define precisely the evolution of the disease. No effect of nutritional status on death on the waiting list was found, ${ }^{22}$ as confirmed by our data; however, $80 \%$ of predicted weight for height is considered a cutoff to predict an increased postoperative mortality.

CF appears to be a disease with many faces; it is a debilitating disease due to malabsorption and metabolic derangement; it is a septic disease; it shows an obstructive pattern, but a restrictive deficit may accompany the functional impairment. Sometimes it can be all of the above at the same time, and sometimes one of these aspects dominates and alters the clinical course toward progressive decline and the possible death of the patient. It is therefore not surprising that the quest for reliable prognostic parameters, especially in compromised patients, is so difficult. No current test is universally applicable; in fact, spirometry and all the other current parameters might well depict the status of one patient while in other cases they could not justify the rapid fatal outcome on the waiting list.

Hemodynamic data obtained in other patients with parenchymal disorders are controversial with regard to outcome. ${ }^{23-25}$ Our data suggest that patients with $\mathrm{CF}$ show a deterioration of pulmonary hemodynamics in the advanced phase of their disease, when it is more likely for the many possible causes (parenchymal destruction, obstructive disease, interstitial fibrosis, left-to-right and right-to-left shunt, hyperdynamic flow) to affect the pulmonary circulation. The occurrence and progression of hemodynamic impairment is thus multifactorial and not surprisingly associated with an increased risk of death on the waiting list. Increased $\mathrm{mPA}$, cardiac output, cardiac index, PAWP, and Qs/Qt indicate a low life expectancy and an increased risk of death within 6 to 8 months, and in this case patients should be considered in the descending phase of the "transplant window" and receive priority for organ allocation. The hyperdynamic pattern recorded in patients dying on the waiting list may recall sepsis and could be attributed to infection; however, no clinical data supported the existence of acute infectious complications at the time of evaluation. This pattern was also shown by most of our patients at the time of transplantation, and these patients underwent successful transplantation without any sign of infection during the early postoperative course. We have also considered the possibility that anxiety during cardiac catheterization at the time of evaluation and immediately before transplantation might have helped to modify pulmonary hemodynamics; however, at the time of transplantation, mPA and cardiac index were confirmed when measurements were repeated after induction of anesthesia and intubation. The Cox proportional hazards model confirmed a trend toward an increased risk of death on the waiting list for most of these variables: however, the multivariate analysis will be extremely useful when a more consistent number of patients and events will be available, to confirm these results and evaluate the independent role of each variable.

Echocardiographic evaluation is an extremely convenient screening test ${ }^{14}$; however, it allows only estimation of systolic pulmonary artery pressure; moderate 


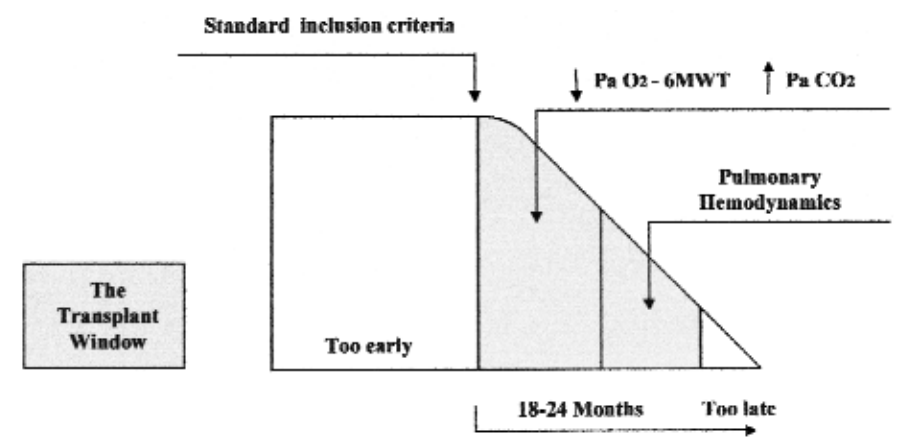

Fig 1. "Transplant window" for patients with $\mathrm{CF}$.

pulmonary hypertension, especially in the presence of obstructive pulmonary disease, may be difficult to detect and rarely is able to correlate with mPA measured at right heart catheterization. The exact assessment of pulmonary hemodynamics, necessary in our opinion for all lung transplant candidates, should rely on right heart catheterization, ${ }^{26}$ which should be electively performed at the time of evaluation. Right heart catheterization is easy to perform, it shows a low rate of complications, and it is well tolerated even in young and pediatric patients.

The "transplant window" for patients with CF could thus be redesigned (Fig 1). Standard criteria, such as $\mathrm{FEV}_{1}$, hypoxia, hypercapnia, increased frequency and severity of exacerbations, and increased frequency of hospitalizations, are useful to include patients on the waiting list. Further deterioration of $\mathrm{PaO}_{2}, \mathrm{PaCO}_{2}$, and 6-minute walk results confirms that each patient has been correctly included in the initial phase of the program waiting for the transplant window. Patients with CF show a deterioration of pulmonary hemodynamics in the advanced phase of their disease, and at that time this deterioration predicts an increased risk of death. These parameters contribute to identifying the individual to be in the second part of the transplant window, and the short life expectancy could indicate a priority for organ allocation.

We thank Maria Luce Vegna for statistical analysis; Isac Flaishman, Serena Quattrucci, Cecilia Coccia, and Edoardo Mercadante for collecting data at the different points of the study; Susanna Sciomer, Angelo Di Roma, and Claudio Iacoboni for performing echocardiography and heart catheterization; and Maurizio Seminara and Mario Passacantilli for preparing tables and illustrations.

\section{REFERENCES}

1. Egan TM. Lung transplantation in cystic fibrosis. Semin Respir Infect 1992;7:227-39.
2. Mendeloff EN, Huddleston CB, Mallory GB, et al. Pediatric and adult lung transplantation for cystic fibrosis. J Thorac Cardiovasc Surg 1998;115:404-14.

3. Ciriaco P, Egan TM, Cairns EL, Thompson JT, Detterbeck FC, Paradowski LJ. Analysis of cystic fibrosis referrals for lung transplantation. Chest 1995;107:1323-7.

4. Milla CE, Warwick WJ. Risk of death in cystic fibrosis patients with severely compromised lung function. Chest 1998;113:1230-4.

5. Kerem E, Reisman J, Carey M, et al. Prediction of mortality in patients with cystic fibrosis. N Engl J Med 1992;326:1187-91.

6. Hayllar KM, Williams SGJ, Wise AE, et al. Prognostic model for prediction of survival in cystic fibrosis. Thorax 1997;52:313-7.

7. Hosenpud JD, Bennett LE, Keck BM, Edwards EB, Novick RJ. Effect of diagnosis on survival benefit of lung transplantation for end-stage lung disease. Lancet 1998;351:24-7.

8. Dark JH. Priorities for lung transplantation. Lancet 1998;351:4-5.

9. Marshall SE, Kramer MR, Lewiston NJ, Starnes VA, Theodore J. Selection and evaluation of recipients for heart-lung and lung transplantation. Chest 1990;1488-94.

10. Sharples L, Belcher C, Dennis C, Higenbottam T, Wallwork J. Who waits longer for heart and lung transplantation? J Heart Lung Transplant 1994;13:282-91.

11. Bommer W, Weinert L, Neumann A, Neef J, Mason DT, De Maria A. Determination of right atrial and right ventricular size by two-dimensional echocardiography. Circulation 1979;60:91100.

12. Hayden AH, Robert RC, Kriett JM, Smith CM, Nicholson K, Jamieson SW. Primary diagnosis predicts prognosis of lung transplant candidates. Transplantation 1993;55:1048-50.

13. Stern RC, Borkat G, Hirschfeld SS, et al. Heart failure in cystic fibrosis: treatment and prognosis of cor pulmonale with failure of the right side of the heart. Am J Dis Child 1980;134:267-72.

14. Moss AJ. The cardiovascular system in cystic fibrosis. Pediatrics 1982;70:728-41.

15. MacLusky I, Levison H. Cystic fibrosis. In: Chernick V, editor. Disorders of the respiratory tract in children. Philadelphia: WB Saunders; 1990. p. 692-729.

16. Nixon PA, Orenstein DM, Kelsey SF, Doershuk CF. The prognostic value of exercise testing in patients with cystic fibrosis. $\mathrm{N}$ Engl J Med 1992;327:1785-8.

17. Kraemer R, Rudeberg A, Hadorn B, Rossi E. Relative underweight in cystic fibrosis and its prognostic value. Acta Pediatr Scand 1978;67:33-7.

18. Gaskin K, Gurwitz D, Durie P, Corey M, Levison H, Forster G. 
Improved respiratory prognosis in patients with cystic fibrosis with normal fat absorption. J Pediatr 1982;100:857-62.

19. Huang NN, Schidlow DW, Szatrowski TH, et al. Clinical features, survival rate and prognostic factors in young adults with cystic fibrosis. Am J Med 1987;82:871-9.

20. Tablan OC, Chorba TL, Schidlow DV, et al. Pseudomonas cepacia colonization in patients with cystic fibrosis: risk factors and clinical outcome. J Pediatr 1985;107:382-7.

21. Kadikar A, Maurer J, Kesten S. The six minute walk test: a guide to assessment for lung transplantation. J Heart Lung Transplant 1997;16:313-9.

22. Sharples L, Hathaway T, Dennis C, Caine N, Higenbottam T, Wallwork J. Prognosis of patients with cystic fibrosis awaiting heat and lung transplantation. J Heart Lung Transplant 1993;12: 669-74.

23. Jazek V. The prognosis and development of pulmonary hypertension in idiopathic diffuse interstitial lung fibrosis. G Ital Cardiol 1984;14:39-45.

24. Weitzenblum E, Ehrhart M, Rosaholinjenehary J, Hirth C. Pulmonary hemodynamics in idiopathic pulmonary fibrosis and other interstitial pulmonary diseases. Respiration 1983;44:118-27.

25. Harari S, Simonneau G, De Juli E, et al. Prognostic value of pulmonary hypertension in patients with chronic interstitial lung disease referred for lung and heart-lung transplantation. J Heart Lung Transplant 1997;16:460-3.

26. Tramarin R, Torbiki A, Marchandise B, Laaban JP, Morpurgo M. Doppler echocardiographic evaluation of pulmonary artery pressure in chronic obstructive pulmonary disease: a European multicentre study. Eur Heart J 1991;12:103-11.

\section{Discussion}

Dr Robert Duane Davis (Durham, NC). Dr Venuta and his colleagues have identified characteristics of those patients with $\mathrm{CF}$ who are going to die before transplantation. What are we going to do with the information? A $24 \%$ mortality for patients on the waiting list is too high. Unfortunately, the patients in the group that are described are dying within 4 months of listing. In the United States, currently we could not do anything with this group of patients. The average waiting times are approaching 2 to 3 years for patients requiring a double lung transplant. Therefore, we have to get to them earlier and then make decisions regarding their stability and whether to proceed with transplantation. Even when it is possible to prioritize on the basis of severity of illness, some patients referred that late in the disease process are not going to survive long enough to undergo transplantation. How are you going to use the information to provide feedback to your pulmonologists and referring physicians so as to improve earlier referral?

Additionally, you are demonstrating that the patients at risk for early mortality have a hypermetabolic state with an increased cardiac index and a decreased systemic vascular resistance. However, pulmonary vascular resistance was only mildly elevated, and the increase was not statistically significant. This raises a couple of questions. Can you do something noninvasively, such as a metabolic heart study, to differentiate the patients either at listing or later? Second, is this just the nature of the infectious aspects of the disease? Are the patients who died earlier more likely to have Burkholderia cepacia or panresistant Pseudomonas? Did they have a greater infectious burden?

How are you going to stratify your patients? Obviously, donor lungs are a limited resource, and you are going to try to use them so as to lessen your overall mortality. How do you triage patients as they enter the evaluation phase and are monitored while waiting? I assume that you do not repeat invasive studies of pulmonary hemodynamics.

This paper reiterates our biggest problem, the limited number of donor organs. We need alternative ways to treat patients when they get sick so that they can live longer, and then we need alternative ways to get more organs for these patients or alternative therapies.

Dr Venuta. Dr Davis, thank you for your comments and questions. I will try to answer them point by point.

The present series represents our initial experience in cooperation with the $\mathrm{CF}$ group at our institution. At the beginning we were able to enroll in our program only a small number of patients, and many of them were at an advanced phase of their disease. As a result, most of the patients either underwent transplantation or died within 6 months. We have shared this information with our referring physicians to persuade them to consider lung transplant candidates at an earlier stage; for this reason, we are now enrolling patients in better condition. However, even if patients with $\mathrm{CF}$ are considered earlier for lung transplantation, we continue to take their hemodynamic pattern extremely seriously. In fact, not more than a few weeks ago we lost a young patient after only 3 months on the waiting list. He was not extremely hypercapnic, the $\mathrm{FEV}_{1}$ was around $25 \%$, but his $\mathrm{mPA}$ was above 40 $\mathrm{mm} \mathrm{Hg}$, confirming the data that we just reported.

Concerning the possible role of sepsis, we have to remember that these patients have chronic infections, and the low systemic vascular resistance may reflect this aspect. We agree that the metabolic state could and should be investigated more extensively. A precise multivariate analysis, which could not be performed in this small series, will certainly add more information in the future. In this series, no patient had an active infection either at the time of evaluation or at the time of transplantation. There was no difference among the three groups in terms of Pseudomonas cepacia colonization.

Triage is an important point. The waiting time is and will be the most important parameter to indicate priority on the waiting list. However, competition for a graft exists among CF patients and also with patients with other diseases, such as pulmonary fibrosis, who are at an increased risk of death during the waiting time. Also, a small number of patients eventually are intubated and wait for the transplant in the intensive care unit. For all these reasons, priority may be indicated according to different parameters; if all the patients on the list and with the same blood group and adequate size are in stable condition, we would probably favor $\mathrm{CF}$ patients with the most deranged hemodynamic pattern.

Dr Thomas M. Egan (Chapel Hill, NC). Your groups were defined according to outcome, and then you used data acquired at the time of evaluation to do your study. Did you 
ever update this information in any of the patients? Given your results, that is, that pulmonary hypertension is associated with a poorer outcome, do you plan to update this information? It would seem that it might be reasonable to perform right heart catheterizations every 3 or 6 months in some of these patients if you can identify the ones who are sicker.

I would also like to raise an issue to which Dr Davis alluded: In the United States if a patient comes to the hospital and dies within 4 months, we cannot do anything about that. Under the current algorithm, that is true. However, the Department of Health and Human Services has instructed UNOS to do something about that, and I am optimistic that maybe we can do something about that. It will be information such as you have provided that will help us sort out who is the sickest and who should be given an opportunity for transplantation over other patients. Frankly, if the patient's condition is far advanced when we first see him or her, we worry about why the patient is such a late referral. In some instances, the patient really did not want to receive a transplant at all and is merely trying to please parents or family members.

Dr Venuta. Thank you, Dr Egan, for your comments and questions.

All of our patients receive echocardiography in adjunct to right heart catheterization at the time of evaluation; this is a cost-effective investigation, and it may be useful in many patients. However, data obtained with the echocardiogram are often different from those obtained with invasive means. We usually update our data with echocardiography every 3 months. We plan to repeat right heart catheterization every year if the patients wait for a long time for transplantation. Since our waiting list is slowly growing, we assume that it will be more common in the future.

Dr Joel D. Cooper (St Louis, Mo). Your group from Rome has been making major contributions to all of the thoracic meetings and I very much enjoyed your presentation.

I want to expand on a point that Dr Egan mentioned. You have used your data to retroactively look at the patient's original status. Obviously, doing this prospectively will be of benefit.

I have two questions. If you had these patients exercise at the outset, could you distinguish between those who had more reserve and those who did not? We have never done that, either in transplant or volume reduction. We measure a static pulmonary artery pressure. We know that when those patients have trouble postoperatively, their pulmonary pressures can sometimes become very high. So I wonder whether a protocol is in order. When you do the right heart catheterizations or studies, do you think having the patients exercise might help you differentiate between those who are at greater risk of having pulmonary hypertensive problems and those who are not?

Second, was there any particular pulmonary artery pressure measurement above which two thirds had problems and below which two thirds did not? Was any particular range indicative, other than just the mean of the group?

Dr Venuta. Dr Cooper, I wish to thank you for your comments and suggestions. It will be interesting to evaluate pulmonary hemodynamics during exercise. We are performing a stress test with dobutamine, but the preliminary results are not yet available. Concerning your second question, according to the World Health Organization, pulmonary hypertension is considered severe when the $\mathrm{mPA}$ is above $25 \mathrm{~mm} \mathrm{Hg}$. In group I we had only 1 patient with moderate pulmonary hypertension $(\mathrm{mPA}<25 \mathrm{~mm} \mathrm{Hg}$ ) and the other 10 patients showed mPAs above $30 \mathrm{~mm} \mathrm{Hg}$. For this reason, $30 \mathrm{~mm} \mathrm{Hg}$ is a good cutoff point, in particular if we consider that only 2 and 3 patients, respectively, in groups II and III had such mPAs.

\section{Online-www.aats.org}

Now you can get The Journal of Thoracic and Cardiovascular Surgery online. The Journal online brings you faster delivery time, easy searching of current and back issues, links to PubMed, AATS, WTSA, and other important sites, and more. Visit the Journal online today.

\section{Receive tables of contents by e-mail}

To receive the tables of contents by e-mail, sign up through our Web site at http://www.mosby.com/jtcvs. Choose E-mail Notification. Simply type your e-mail address in the box and click the Subscription button.

Alternatively, you may send an e-mail message to majordomo@mosby.com. Leave the subject line blank and type the following as the body of your message: subscribe jtcvs_toc.

You will receive an e-mail to confirm that you have been added to the mailing list. Note that table of contents e-mails will be sent out when a new issue is posted to the Web. 